\title{
Crescimento vegetativo, produção de fitomassa e de óleo essencial de Melissa officinalis L. sob diferentes lâminas de irrigação
}

\author{
Vegetative growth, phytomass and essential oil yield of Melissa officinalis L. under different \\ irrigation levels \\ Messulan Rodrigues Meira ${ }^{I^{*}}$ Marco Túlio Pinheiro de Melo ${ }^{\mathrm{I}}$ Ernane Ronie Martins ${ }^{\mathrm{I}}$ Mateus \\ Junior da Silva Pinto ${ }^{I}$ Cinthya Souza Santana ${ }^{I}$
}

\section{RESUMO}

O objetivo deste estudo foi avaliar a produção de fitomassa e óleo essencial da M. officinalis $L$. com lâminas de irrigação no Norte de Minas Gerais como medidas de uso racional da água. O delineamento experimental utilizado foi o inteiramente ao acaso em parcelas subdivididas no tempo, com seis tratamentos definidos pelas lâminas de irrigação $(T 1=0,50 x E T 0 ; \quad T 2=0,75 x E T 0 ; \quad T 3=1,0 x E T 0 ; \quad T 4=1,25 x E T 0 ;$ $T 5=1,5 x E T 0$ e T6=1,75xETO), e quatro repetições. $O$ estudo foi conduzido em microlisímetros. Com base na análise de regressão, observou-se que o crescimento e a produção de fitomassa foram influenciados pela disponibilidade hídrica. Maior produção e teor de óleo essencial foram conseguidos na menor lâmina e a época de avaliação não influenciou na aplicação das lâminas.

Palavras-chave: plantas medicinais, evapotranspiração, estresse hídrico.

\section{ABSTRACT}

The objective of this study has been to evaluate the essential oil production of Melissa officinalis L. with irrigation blade in the North of Minas Gerais as a measure of water rational use. The experimental design has been completely randomized in subdivided plots in the time with six treatments, defined by irrigation blade (T1=0,50xET0; T2=0,75xET0; T3=1,0xET0; T4=1,25xET0; T5=1,5xET0 e T6=1,75 x ETO), and four replications. The study has been conducted at the micro lysimeter. Based on regression analysis, it has been observed that the fitomass production and growth was influenced by water availability. The production and content of the essential oil are inversely proportional to the increase in the irrigation blade. The production of biomass has been obtained from the smaller blade and the evaluation times did not influenciate on their blades.

Key words: medicinal plants, evapotranspiration, water stress.

\section{INTRODUÇÃO}

A melissa (Melissa officinalis L.), espécie da família Lamiaceae, conhecida como ervacidreira verdadeira, é uma planta herbácea de até $100 \mathrm{~cm}$ de altura, perene, rizomatosa, aromática, de caule quadrangular e piloso. Sua propagação é por sementes e vegetativamente por estaquia e divisão de rizomas. Por ser uma planta de clima frio, de acordo com as condições climáticas e disponibilidade de nutrientes, a germinação pode variar de sete a 21 dias. Seu ciclo de vida varia de 90 dias, no verão, a 120 dias no inverno (LORENZI \& MATOS, 2002 e COUTO, 2006). A planta possui característica de plasticidade fenotípica sob altas temperaturas, em que acelera o desenvolvimento fenológico, a fim de garantir a reprodução da espécie (BORTOLO et al., 2009). Apesar das adaptações da planta no local de origem, por questões climáticas, a melissa não floresce no Brasil (LORENZI \& MATOS, 2002).

$\mathrm{O}$ bom desenvolvimento da planta depende das condições favoráveis do ambiente como: a incidência luminosa, a temperatura e a irrigação, devendo esta ser fornecida de acordo com a necessidade de cada espécie, para que o excesso não impeça a oxigenação em suas raízes, reduzindo, dessa forma, suas atividades metabólicas (BORGES \& RENA, 1993).

A espécie sob boas condições de irrigação garante ótimos desempenhos no estágio

'Laboratório de Plantas Medicinais, Instituto de Ciências Agrárias (ICA), Universidade Federal de Minas Gerais (UFMG), CP 135, 39404-006, Montes Claros, MG, Brasil. E-mail: messulan.meira@ gmail.com. * Autor para correspondência. 
vegetativo, aumentando a área foliar e produção de folhas, bem como crescimento em altura. O bom desenvolvimento da espécie no Norte de Minas Gerais depende de irrigações constantes devido a altas temperaturas da região. Apesar do crescimento da espécie ser positivo, a produção de óleo essencial é reduzida sob irrigação plena (MEIRA et al., 2011). Para a produção de óleo essencial, a irrigação deve ser suspensa, pois, em situações de estresse, o carbono fixado fotossinteticamente da síntese de metabólitos primários é redirecionado para a síntese de metabólitos secundários como os compostos fenólicos e terpenoides (ABREL \& MAZZAFERA, 2005). Os óleos essenciais são exemplo de compostos terpenoides, tendo o isopreno como sua principal característica, originado da rota do ácido mevalônico. Esses óleos, sob baixas condições hídricas, protegem a planta contra ataque de insetos herbívoros, propiciando melhores condições de sobrevivência (TAIZ \& ZEIGER, 2009).

$\mathrm{Na}$ melissa, os óleos estão presentes nos tricomas secretores das folhas e flores, onde apresentam os compostos $\alpha$ e $\beta$ citral, derivados do isopreno, como majoritário (SADRAEI et al., 2003), cuja ação é relaxante e indutora do sono, sendo os compostos majoritários do óleo essencial de maior interesse pelas indústrias farmacêuticas (MAY et al., 2008).

É sabido que a água é um recurso natural, essencial para a existência da vida no planeta, que, além de ser cara para o consumidor, está condenada à escassez pelo mau uso. É o fator limitante para o desenvolvimento agrícola, já que mais de $70 \%$ de seu volume é consumido mundialmente para essas práticas e que a falta ou excesso desta afeta a produção das plantas (CRISTOFIDIS, 2007).

A melhor forma de manejar a água na agricultura é através de técnicas adequadas de irrigação. As lâminas de água, por exemplo, representam a capacidade de armazenamento no solo para situações específicas de drenagem, visando à rentabilidade da cultura. O uso racional da água por meio de aplicações de lâminas pode ser uma boa alternativa de produção e sustentabilidade (PIRES et al., 2000). Assim, para atender à demanda comercial do produto originado do metabolismo secundário, bem como o uso racional da água na irrigação da espécie, objetivou-se avaliar a produção de fitomassa e óleo essencial da M. officinalis L. com lâminas de irrigação no Norte de Minas Gerais como medidas de uso racional da água.

\section{MATERIAL E MÉTODOS}

Na determinação das lâminas de irrigação, foram construídos microlisímetros utilizandose vasos plásticos de oito litros e diâmetro de $21,65 \mathrm{~cm}$ na abertura. $\mathrm{O}$ delineamento experimental utilizado foi o inteiramente ao acaso em parcelas subdivididas no tempo $(20,35,50,65$ e 80 dias após o transplantio), com seis tratamentos definidos pelas lâminas de irrigação (T1=0,50.ET0; T2=0,75. ET0; T3=1,0.ET0; T4=1,25.ET0; T5=1,5.ET0 e T6=1,75.ETO) e quatro repetições. Antes de iniciar o experimento, o solo de cada parcela experimental foi saturado e os vasos foram tampados a fim de se obter a capacidade de campo após a drenagem total, que ocorreu quatro dias depois da saturação. Em seguida, foram transplantadas as mudas produzidas com sementes adquiridas da empresa ISLA ${ }^{\circledR}, 60$ dias após a semeadura.

As irrigações realizadas basearamse na evapotranspiração de referência (ET0), calculada segundo a equação de Hargreaves-Samani (PEREIRA et al., 1997), a partir da qual aplicaramse os coeficientes correspondentes a cada tratamento, sendo o turno de rega de dois dias iniciando cinco dias após o transplantio. Ao final do experimento, determinou-se a evapotranspiração total de cada planta, utilizando-se a equação do balanço de água no solo. As variáveis de crescimento vegetativo como altura, diâmetro e número de folhas foram avaliadas 15 dias após o início da aplicação do turno de rega e, a partir da primeira avaliação, essas foram quinzenais até o 80 dia após o transplantio das mudas. Após obtenção dessas medidas, realizou-se a colheita do material vegetal, o qual foi conduzido para o Laboratório de Plantas Medicinais do ICA/ UFMG, onde foi determinada a fitomassa fresca $(\mathrm{g})$. A extração do óleo foi realizada no Laboratório de Plantas Medicinais do ICA/UFMG, onde $100 \mathrm{~g}$ de folhas frescas foram hidrodestiladas por três horas em aparelho do tipo Clevenger, adaptado a um balão de fundo redondo com capacidade de $1.000 \mathrm{~mL}$ (MING et al., 1996). Após a extração, as folhas foram acondicionadas em saco de papel pardo e seco em estufa de circulação forçada, a $60^{\circ} \mathrm{C}$ até peso constante para a determinação da massa seca. O teor de óleo foi calculado com base na massa seca pela fórmula: $\mathrm{T} \%=$ óleo $(\mathrm{ml}) /$ massa seca $(\mathrm{g}) * 100$ (BOTREL et al., 2010). Concluídas as avaliações, antes da realização da análise de variância, fez-se uma análise exploratória, utilizando o teste de Cochran e Bartlett dos dados para identificação da homogeneidade entre as variâncias dos resultados. Como os resultados 
mostraram que há homogeneidade para o nível de $1 \%$ de significância, então os dados foram submetidos à análise de regressão, sendo as equações ajustadas com base na significância dos coeficientes de regressão pelo teste $\mathrm{t}$, utilizando o software SAS V.8.

\section{RESULTADOS E DISCUSSÃO}

As lâminas de irrigação e o tempo apresentaram influência significativa no crescimento vegetativo e desenvolvimento da melissa (Melissa officinalis L.). As variáveis altura, número de folhas, fitomassa fresca e seca e diâmetro apresentaram comportamento linear positivo, desenvolvendo-se à medida que aumentaram as lâminas de irrigação. A produção e teor de óleo essencial apresentaram comportamento linear negativo, já que a maior produção foi na aplicação da menor lâmina (Figuras $1,2$ e 3$)$.

A altura e o número de folhas da planta apresentaram, inicialmente, comportamento similar em relação às lâminas de irrigação, o que pode ser explicado pelo baixo consumo de água inicial da cultura (Figuras 1 a e 1 b) (PEREIRA et al., 1997). Resultados similares foram observados por SOUSA et al. (2008), ao trabalharem com algodão herbáceo (Gossypium spp.), já que o crescimento da planta e o número de folhas foram afetados positivamente pelas lâminas de irrigação. De acordo com CASTRO et al. (2005), esse resultado pode relacionar-se ao fato de plantas sob boas condições de irrigação apresentarem crescimento superior aos tratamentos sob déficit hídrico e, consequentemente, serem maiores.

O estresse, contrário da boa disponibilidade hídrica, induz à redução do número de folhas, sendo essa uma estratégia de sobrevivência para reduzir a perda de água por transpiração. Assim, há uma redução na taxa fotossintética e, com isso, menor crescimento da planta (TAIZ \& ZEIGER, 2009). Essa mesma observação foi feita em experimento com Hyptis pectinata L., espécie da mesma família, em que a planta teve sua massa foliar reduzida à medida que intensificou o estresse hídrico, pois o déficit de água induziu ao abortamento das folhas pelas plantas como mecanismo de adaptação à condição exposta (SANTOS et al., 2004).

A produção de fitomassa fresca e seca apresentou incremento em função do aumento da lâmina d'água aplicada (Figura 2 a). LOPES et al. (2011) associam esse resultado a fortes radiações sob boas condições hídricas, o que faz aumentar o consumo de água por transpiração e consequentemente a produção de massa seca, contribuindo também para a absorção de nutrientes. MARQUES et al. (2009) corroboram os autores ao afirmarem que fortes radiações favorecem a produção de fitomassa seca, pois, ao cultivarem orégano, observaram que a irrigação bem sucedida apresenta maiores rendimentos econômicos, aumentando em até 24 vezes a produtividade de biomassa em relação às demais culturas. $\mathrm{O}$ resultado condiz com ABBASZADEH et al. (2009) e FARAHANI et al. (2009), em experimentos com M. officinalis, que observaram semelhança nos parâmetros avaliados das plantas sob boas condições ambientais, pois estas concentram energia na produção de metabólitos primários, os quais são essenciais para o desempenho vegetal, aumentando a produção da parte aérea no estágio de desenvolvimento. Já para o Ocimum basilicum L., da mesma família, dentre as lâminas $0,50,75,100$ e $150 \%$ de evapotranspiração em tanque de classe A (ECA), a maior produção de fitomassa fresca e seca ocorreu na lâmina de $100 \%$ (PRAVUSCHI et al., 2010).

Assim como boas condições ambientais beneficiam a produção de fitomassa, condições adversas favorecem a produção de óleo essencial. Essa observação foi feita a partir dos resultados da produção (ml) e teor (\%) de óleo essencial que foram reduzidos nas maiores lâminas aplicadas (Figura 2 b). $\mathrm{O}$ mesmo ocorreu em lâminas aplicadas à cultura de Lippia sidoides Cham., em que o teor de óleo essencial diminuiu linearmente, seguindo o estresse hídrico, alcançando uma redução diária de aproximadamente $50 \%$ de óleo essencial (ALVARENGA et al., 2011). Esse resultado corrobora os observados por ABREU \& MAZZAFERA (2005) e SILVA et al. (2002) em trabalhos realizados com Hypericum brasiliense Choysi e Melaleuca alternifólia Cheel, nos quais perceberam que, em condições de déficit hídrico, houve redução na produção de biomassa e aumento do conteúdo de compostos químicos, principalmente de compostos fenólicos como os óleos essenciais. Para ABBASZADEH et al. (2009) e FARAHANI et al. (2009), a falta de irrigação em algumas plantas diminui o teor de óleo essencial, refutando o resultado observado para a melissa, na qual regimes hídricos restritos aumentaram a sua concentração. Porém, os autores afirmam que, em caso de secas prolongadas, poderá ocorrer perda total do óleo, bem como a morte da planta (TAIZ \& ZEIGER, 2009).

Em relação ao diâmetro do caule (Figura 3), pode-se observar que houve uma tendência de incremento nas lâminas da extremidade. As lâminas 1,25 ET0 e 0,75 ET0, apresentaram as menores

Ciência Rural, v.43, n.5, mai, 2013. 


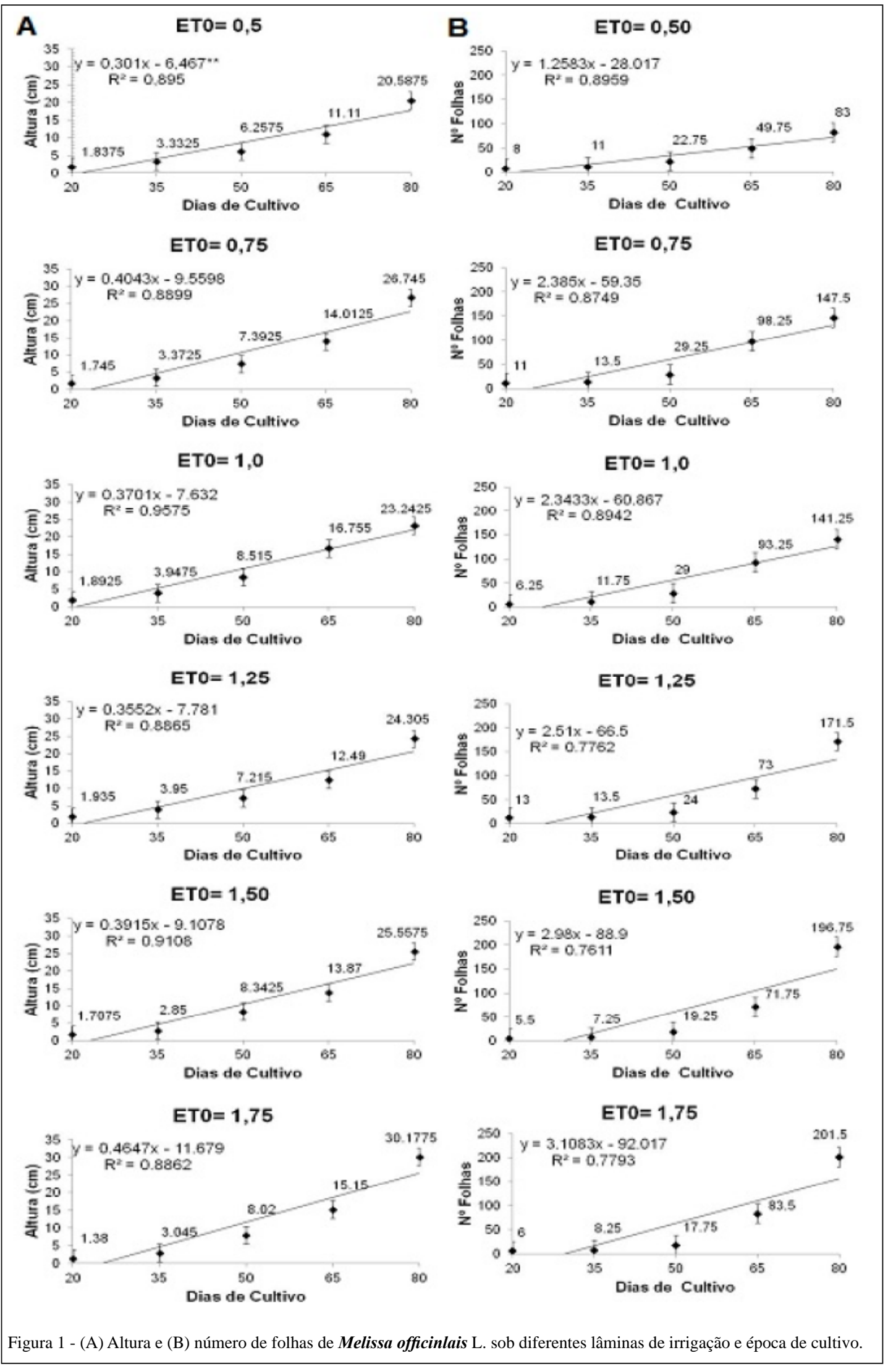

Ciência Rural, v.43, n.5, mai, 2013. 


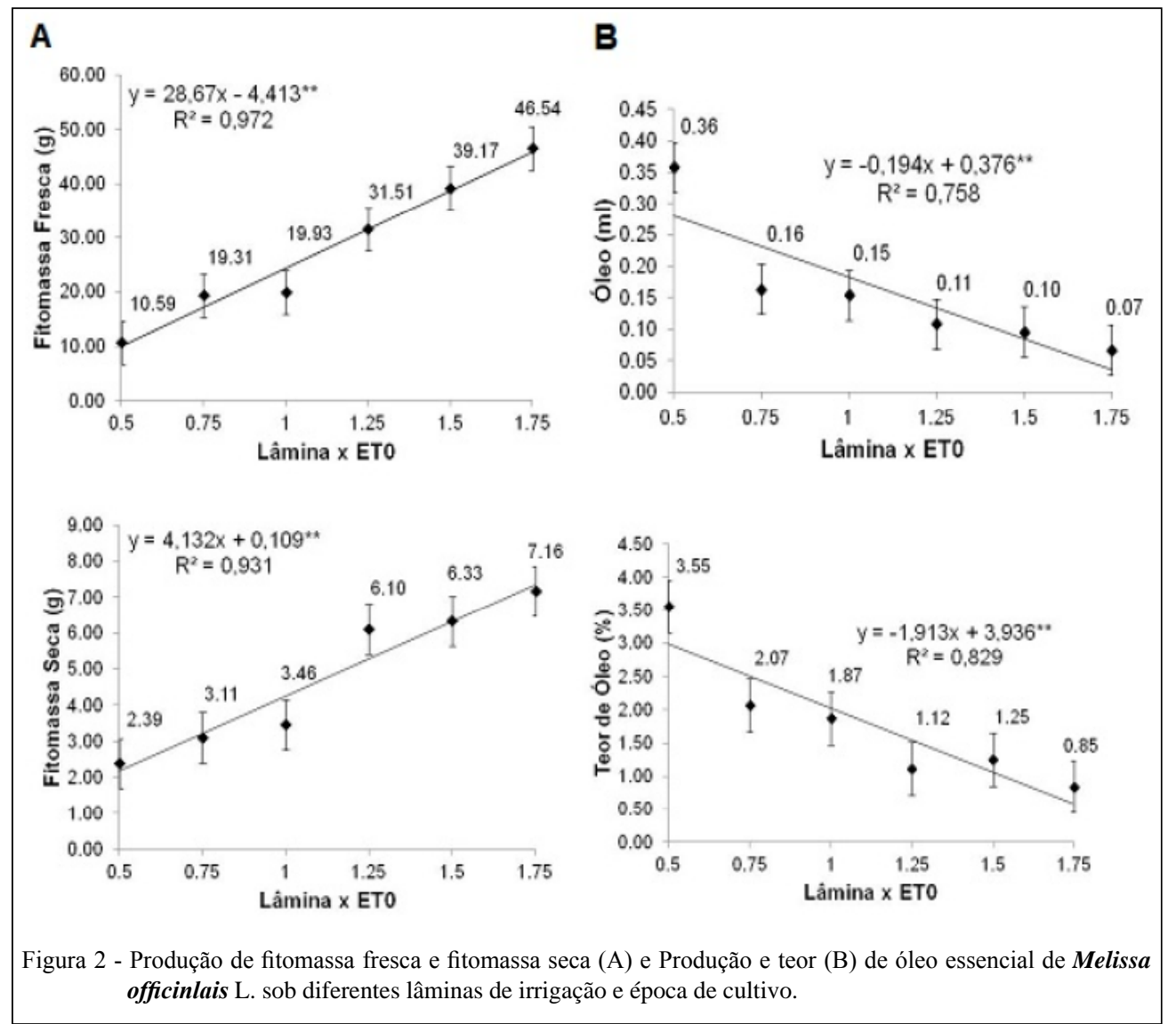

e maiores médias, respectivamente. As lâminas 1,50 ET0 e 1,75 ET0 apresentaram semelhança no incremento em diâmetro. Na lâmina com 1,25 ET0, a irrigação aplicada prejudicou o desenvolvimento. Sendo assim, a segunda (0,75 ET0) apresentou a lâmina de água adequada para aumentar a espessura do caule. A explicação pode estar relacionada ao investimento de metabólitos primários na emissão de folhas (Figura $1 \mathrm{~b}$ ). Resultados contrastantes foram observados por SOUSA et al. (2008) ao trabalharem com Gossypium spp., em que observaram o aumento do diâmetro em função do aumento da quantidade de água, corroborando ALVES et al. (2000) em experimento com Coffea arabica L., quando avaliaram lâminas de irrigação: 0; 0,8;0,6 e 0,4 de evaporação do tanque classe A (ECA) em função da adubação com $\mathrm{N}$ e K. A diferença de resposta entre as lâminas de água aplicadas a diferentes culturas devese à peculiaridade da espécie, pois as duas culturas trabalhadas pelos autores supracitados são lenhosas, enquanto que a melissa é uma espécie herbácea, em que a exigência da planta requer temperatura e umidade ideal para alcançar o sucesso de produção.
A evapotranspiração real da cultura para altura, no de folhas e diâmetro (Figura 1 e 3 ) foi semelhante até a segunda avaliação, ou seja, $20^{\circ}$ e $35^{\circ}$ dia de cultivo para todas as lâminas aplicadas, destacando-se na lâmina de 1,25 ET0. Porém, o diâmetro se estabilizou em crescimento na última avaliação ao $80^{\circ}$ dia para favorecer o crescimento e a emissão de folhas. Apesar do crescimento inicial variar com a exigência de cada espécie, essa experiência é validada por COSTA FILHO et al. (2006), que, em experimento com Ocimum gratissimum L. sob diferentes regimes hídricos (0, 50, 75 e $100 \%$ de água), observaram o mesmo crescimento semanal para todas as lâminas até a terceira semana, ou seja, 21 dias após o transplantio. Esse é o período inicial de crescimento em que as plantas apresentam praticamente a mesma exigência hídrica e que mesmo as menores lâminas aplicadas foram suficientes para permitir o crescimento em níveis satisfatórios. Após esse período, a irrigação influenciou significativamente no crescimento vegetativo das plantas em cada tratamento.

Ciência Rural, v.43, n.5, mai, 2013. 


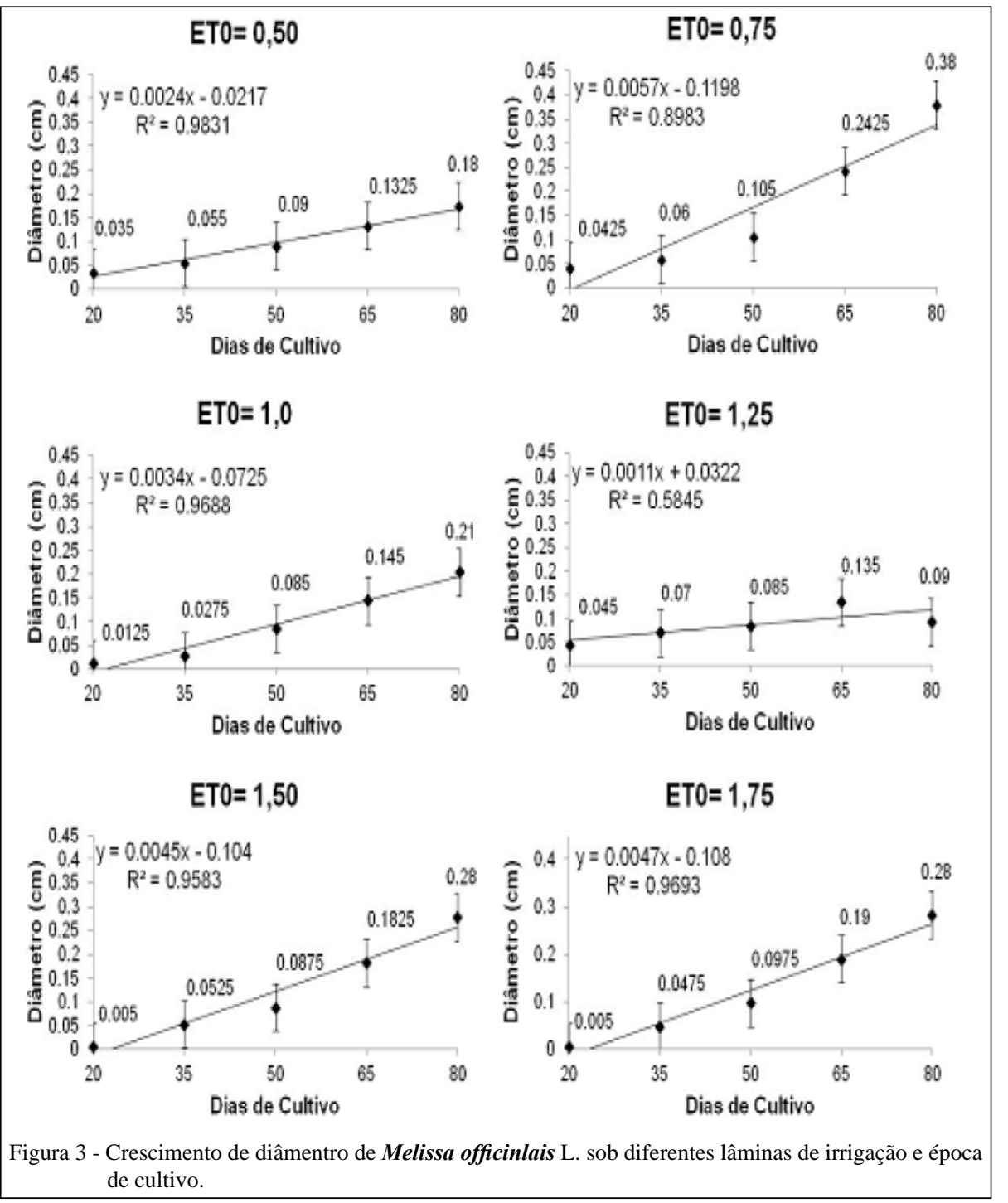

Embora o desenvolvimento do cultivo sob diferentes lâminas de irrigação tenha apresentado o mesmo comportamento, em que a maior produção de biomassas foi através do maior tempo de cultivo, deve-se atentar para irrigação de culturas da família Lamiaceae, a fim de não onerar o custo de produção, visto que a água é um bem de custo elevado e que sua aplicação em excesso, além de não ser fator limitante para a espécie, como a alta temperatura, acarretará maiores perdas tanto por evaporação quanto por percolação, além de reduzir a produção de óleo essencial (LOPES et al., 2011).

\section{CONCLUSÃO}

$\mathrm{O}$ crescimento e a produção de fitomassa são influenciados pela disponibilidade hídrica. A melhor produção de óleo e teor é obtida na menor lâmina aplicada de 0,50 x ET0. De modo geral, no estágio inicial, as plantas apresentaram semelhança de crescimento e a época de avaliação não influencia na aplicação das lâminas.

\section{REFERÊNCIAS}

ABBASZADEH, B. et al. Effects of irrigation levels on essential oil of balm (Melissa officinalis L.). American-Eurasian Journal 
of Sustainable Agriculture, v.3, n.1, p.53-56, 2009. Disponível em: 〈http://www.aensionline.com/aejsa/2009/53-56.pdf>. Acesso em: 01 jan. 2011

ABREU, I.N.; MAZZAFERA, P. Effect of water and temperature stress on the content of active constituents of Hypericum brasiliense Choisy. Plant Physiology and Biochemistry, v.43, n.3, p.241-248, 2005. Disponível em: <http://dx.doi.org/10.1016/j. plaphy.2005.01.020>. Acesso em: 20 maio, 2012. doi: .10.1016/j. plaphy.2005.01.020.

ALVARENGA, I.C.A. et al. Water stress before haverst of pepperrosmarin. Pesquisa Agropecuária Brasileira, v.46, n.7, p.706711, 2011. Disponível em: <http://dx.doi.org/10.1590/S0100204X2011000700005>. Acesso em: 06 jan. 2012. doi: 10.1590/ S0100-204X2011000700005.

ALVES, M.E.B. et al. Crescimento do cafeeiro sob diferentes lâminas de irrigação e fertirrigação. Revista Brasileira de Engenharia Agrícola e Ambiental, v.4, n.2, p.219-225, 2000. Disponível em: <http://www.agriambi.com.br/revista/v4n2/219. Pdf $>$. Acesso em: 06 jan. 2012

BORGES, E.E.L.; RENA, A.B. Germinação de sementes. In AGUIAR, I.B. et al. Sementes florestais tropicais. Brasília: ABRATES, 1993. p.83-136.

BORTOLO, D.P.G. et al. Teor e rendimento de flavonóides em calêndula (Calendula officinalis L.) cultivada com diferentes lâminas de irrigação. Revista Brasileira de Plantas Medicinais, v.11, n.4, p.435-441, 2009

BOTREL, P.P. et al. Variações no teor e na composição volátil de Hyptis marrubioides EPL. cultivada no campo e em casa de vegetação. Química Nova, v.33, n.1, p.33-37, 2010.

CASTRO, P.R.C. et al. Manual de fisiologia vegetal: teoria e prática. São Paulo: Agronômica Ceres, 2005. 651p

COSTA FILHO, L.O. et al. Influência hídrica e térmica no crescimento e desenvolvimento de Ocimum gratissimum L. Revista Brasileira de Plantas Medicinais, v.8, n.2, p.8-13, 2006.

COUTO, M.E.O. Coleção de plantas medicinais aromáticas e condimentares. Pelotas: Embrapa Clima Temperado, 2006. 91p. (Documentos 157).

CRISTOFIDIS, D. Água: um desafio para a sustentabilidade do setor agropecuário. Série Irrigação e Água I. Agrianual, Instituto FNP, v.11, p.37-42, 2007. ISSN 1807157-0. Disponível em: <http//:www.ifnp.og.br>. Acesso em: 20 maio, 2012.

FARAHANI, H.A. et al. Evaluation changing of essential oil of balm (Melissa officinalis L.) under water deficit stress conditions. Journal of Medicinal Plants Research, v.3, n.5, p.329-333, 2009. Disponível em: <http//:www.acaddemicjournals.org/jmpr/ contentes/2009cont/May.htm〉. Acesso em: 17 jan. 2012.

LORENZI, H.; MATOS, F.J.A. Plantas medicinais do Brasil: nativas e exóticas. Nova Odesa: PLANARUM, 2002. 544p.

LOPES, O.D. et al. Determinação do coeficiente de cultura (Kc) e eficiência do uso de água do alecrim-pimenta irrigado. Revista Brasileira de Engenharia Agrícola e Ambiental, v.15, n.6, p.548-553, 2011. Disponível em: <http://www.agriambi com.br/index.php?option=com_content \&view $=$ article $\&$ id $=18$
\&Itemid=11>. Acesso em: 10 jan. 2012. doi: 10.1590/S141543662011000600002 .

MARQUES, P.A.A. et al. Orégano production under various water depths estimated by means of the class A pan evaporation. Horticultura Brasileira, v.27, p.59-63, 2009. Disponível em: <http://dx.doi.org/10.1590/S0102-05362009000100012〉. Acesso em: 17 jan. 2012. doi: 10.1590/S0102-05362009000100012.

MAY, A. et al. Produtividade da biomassa de melissa em função de intervalo de cortes e doses de nitrogênio. Horticultura Brasileira, v.26, p.12-315, 2008. Disponível em: <http://dx.doi.org/10.1590/ S0102-05362008000300004>. Acesso em: 15 jan. 2012. doi: $10.1590 / \mathrm{S} 0102-05362008000300004$.

MEIRA, M.R. et al. Crescimento e produção de óleo essencial de Melissa officinalis L. nas condições climáticas de Montes Claros - MG. Biotemas, v.24, n.1, p.1-8, 2011. Disponível em: <http:// www.biotemas.ufsc.br/volumes/pdf/volume241/1a8.pdf >. Acesso em: 23 maio, 2012. doi:10.5007/2175-7925.2011v24n1p1.

MING, L.C. et al. Yeld of essential oil and citral content in different parts of lemongrass leaves (Cymbopongon citratus (Dc.) Stapf.) Poaceae. In: INTERNATIONAL SYMPOSIUM ON MEDICINAL AND AROMATIC PLANTS, 1996. ISHS Acta Horticulturae, v.426, p.555-559, 1996. Disponível em: <http:// www.actahort.org/members/showpdf?booknrarnr $=426 \_60>$. Acesso em: 10 jan. 2012.

PEREIRA, A.R. et al. Evapotranspiração. Piracicaba: FEALQ, 1997. 183p.

PIRES, R.C.M. et al. Manejo da irrigação em hortliças. Horticultura Brasileira, v.18, supl, p.147-158, 2000.

PRAVUSCHI, P.R. et al. Efeito de diferentes laminas de irrigação na produção de óleo essencial do manjericão (Ocimum basilicum L.). Acta Scientiarum Agronomy, v.32, n.4, p.687-693, 2010. Disponível em: <http://dx.doi.org/10.4025/actasciagron. v32i4.3160>. Acesso em: 20 maio, 2012. doi:10.4025/ actasciagron.v32i4.3160.

SADRAEI, H. et al. Relaxant effect of essential oil of Melissa officinalis and citral on rat ileum contractions. Fitoterapia, v.74, n.5, p.445-452, 2003. Disponível em: <http://dx.doi.org/10.1016/ S0367-326X(03)00109-6>. Acesso em: 17 jan. 2012. doi: $10.1016 / \mathrm{S} 0367-326 \mathrm{X}(03) 00109-6$.

SANTOS, T.T. et al. Efeito do estresse hídrico na produção de massa foliar e teor de óleo essencial em sambacaitá (Hyptis pectinata L.). In: CONGRESSO BRASILEIRO DE OLERICULTURA, 2004, Campo Grande, RS. Anais... Campo Grande: Congresso de Olericultura, 2004. V.22, p.1-4

SILVA, S.R.S. et al. Efeito do estresse hídrico sobre características de crescimento e a produção de óleo essencial de (Melaleuca alternifolia Cheel). Acta Scientiarum, v.24, p.1363-1368, 2002. Disponível em: <http//:eduem.uem.br/ojs/index.php/ActaSciAgron/ article/download/.../1790>. Acesso em: 10 jan. 2012.

SOUSA, P.S. et al. Efeito de lâminas de irrigação sobre o crescimento do algodoeiro herbáceo. Revista Verde, v.3, n.3, p.0611, 2008. Disponível em: <http://www.gvaa.com.br/revista/index. php/RVADS/article/viewFile/105/105>. Acesso em: 09 jan. 2012.

TAIZ, L; ZEIGER, E. Fisiologia vegetal. 4.ed. Porto Alegre: ARTMED. 2009. 719p.

Ciência Rural, v.43, n.5, mai, 2013. 